\title{
Thierry Poyet (textes réunis et présentés par), Flaubert et les artistes de son temps. Éléments pour une conversation entre écrivains, peintres et musiciens
}

\section{Maria Emanuela Raffi}

\section{(C) OpenEdition}

\section{Journals}

\section{Edizione digitale}

URL: http://journals.openedition.org/studifrancesi/5715

DOI: 10.4000/studifrancesi.5715

ISSN: 2421-5856

\section{Editore}

Rosenberg \& Sellier

\section{Edizione cartacea}

Data di pubblicazione: 1 septembre 2011

Paginazione: 444

ISSN: 0039-2944

\section{Notizia bibliografica digitale}

Maria Emanuela Raffi, «Thierry Poyet (textes réunis et présentés par), Flaubert et les artistes de son

temps. Éléments pour une conversation entre écrivains, peintres et musiciens», Studi Francesi [Online], 164 (LV | II) | 2011, online dal 30 novembre 2015, consultato il 13 janvier 2021. URL: http://

journals.openedition.org/studifrancesi/5715 ; DOl: https://doi.org/10.4000/studifrancesi.5715

Questo documento è stato generato automaticamente il 13 janvier 2021.

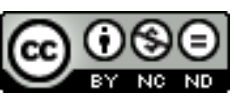

Studi Francesi è distribuita con Licenza Creative Commons Attribuzione - Non commerciale - Non opere derivate 4.0 Internazionale. 


\title{
Thierry Poyet (textes réunis et présentés par), Flaubert et les artistes de son temps. Éléments pour une conversation entre écrivains, peintres et musiciens
}

\author{
Maria Emanuela Raffi
}

\section{NOTIZIA}

THIERRY POYET (textes réunis et présentés par), Flaubert et les artistes de son temps. Éléments pour une conversation entre écrivains, peintres et musiciens, Paris, Eurédit, 2010, 292 pp.

1 Nella Présentation della raccolta, Thierry POYET traccia l'itinerario della scrittura flaubertiana, intesa prima come rifiuto della contemporaneità, poi, progressivamente, come esercizio meno solitario, più legato alle innumerevoli letture dei classici e alla frequentazione delle altre arti. Nell'articolo immediatamente successivo-Peinture et peintres dans la correspondance de Flaubert: un singulier regard, pp. 27-52-, che apre la sezione «Flaubert et les arts: peinture et musique», lo stesso Poyet illustra ampiamente le relazioni di Flaubert con la pittura, sia con le opere consacrate dalla tradizione (Bruegel, Michelangelo, Tiziano, Rubens, Rembrandt e altri), sia, in modo assai più ridotto, con la pittura contemporanea esposta nei Salons. Se i nomi dei pittori più famosi non figurano nella corrispondenza flaubertiana, sono presenti invece molti nomi meno conosciuti, fra cui spicca quello della nipote Caroline de Commanville a testimoniare il suo interesse per l'artista, «être supérieur» e il suo disinteresse per «son type d'expression».

2 In Images de femmes: "Madame Bovary" et la peinture de genre sous le Second Empire (pp. 53-72), Michaël votTERo mostra i legami che intercorrono fra la figura di Emma Bovary e 
le illustrazioni pittoriche «de la femme moderne surprise dans ses activités quotidiennes» esposte nel Salon del 1857. Per l'uno, il romanziere, come per gli altri, i pittori di genere e particolarmente Stevens, la fonte di ispirazione è la stampa illustrata, che Flaubert frequentava, oltre alle incisioni di Gavarni, espressione dell'esistenza ripetitiva della «femme bourgeoise».

Pascal RANNOU prende in esame nel suo contributo le osservazioni sull'arte espresse da Flaubert nel suo viaggio in Bretagna con Maxime Du Camp ("Par les champs et par les grèves": Flaubert critique d'art "sur le motif», pp. 73-91). "Le regard critique tempère souvent le lyrisme-scrive Rannou-sans entraver le bonheur de son expression. Flaubert se montre dans Par les champs et par les grèves ennemi de la vulgarité et de l'art officiel. Mais il défend aussi le naturel roman et l'authenticité de l'art populaire».

Flaubert et les Goncourt coloristes: regard sur Paris et Barbizon di Justine Jотнам (pp. 93-111) propone una lettura 'pittorica' dell'opera letteraria di Flaubert e dei Goncourt, tre autori uniti secondo l'A. dalla stessa straordinaria capacità di «vision et figuration»e dallo stesso gusto del colore, che li oppone ai partigiani del disegno nel dibattito sulla pittura. L'Education sentimentale e Manette Salomon vengono quindi analizzati come «vues chromatiques» prodotte da un «œil artiste» particolarmente esperto in «poétisation de la vue».

5 Il rapporto di Flaubert con la musica e i rappresentanti dell'arte musicale è l'oggetto dello studio di Luís Carlos PIMENTA GONÇALVES, Références à la musique et au milieu musical dans la correspondance de Flaubert (pp. 113-127). Oltre che degli studi musicali di Caroline, sorella di Flaubert, la corrispondenza tratta dei rapporti dello scrittore con cantanti e compositori e soprattutto con Berlioz, particolarmente attratto da Salammbô, la cui versione musicale sarà però realizzata da Ernest Reyer.

6 La seconda sezione, «Flaubert face à ses confrères écrivains», prende avvio con un saggio di Angeliki GIANNOULI (Louis Bouilhet, auteur dramatique, pp. 131-158), che presenta e analizza l'opera teatrale di Louis Bouilhet, caro amico di Flaubert e autore soprattutto di drammi storici e di ambientazione borghese di un qualche successo all'epoca, ma rapidamente dimenticati dopo la sua morte nel 1869.

7 Lectures de Flaubert: Maupassant face à Sand (pp. 159-184) di Maria GUGLIOTTA ha come oggetto la raccolta di lettere di Flaubert a George Sand pubblicate nel 1884 con la prefazione di Maupassant. Divenuta la corrispondente privilegiata di Flaubert dopo la morte di Louis Bouilhet, Sand appare come «l'alter ego de Flaubert pour ses doctrines, ses principes, et ses conceptions philosophiques de l'existence» anche se non ne condivide il pessimismo e la «désolation», che Maupassant traduce come «impassibilité», espressione di «une morale artiste supérieure à la morale courante».

In La tentation critique de Flaubert: «pohètes» et littérateurs au temps de Madame Bovary (pp. 185-212) Marie BAUDRY analizza il contesto di letture e frequentazioni in cui nasce l'opera fondamentale di Flaubert, Madame Bovary, quale appare dalla corrispondenza dell'autore. Una storia e una teoria del romanzo si disegnano dietro e dentro l'assiduo esercizio di Flaubert lettore, che fa di Madame Bovary un luogo totalizzante, dove convergono prosa, poesia e critica letteraria.

Aurélia HeTzel (La Reine de Saba dans "La Tentation de Saint Antoine": à la croisée des textes, pp. 213-227) analizza l'episodio dell'apparizione della Regina di Saba, figura complessa, modellata da una lunga tradizione, soprattutto ebraica e musulmana, oltre che dalla sua derivazione biblica. Riscrittura di un mito, essa diventa attraverso la 
ripresa di Flaubert un nuovo modello simbolista e decadente, celebrato da Durtal e ripreso in letteratura fino a Butor.

10 L'immobile pienezza e perfezione del Midi nei testi poetici di Bouilhet e di Leconte de Lisle, poeti amati da Flaubert, è il punto di partenza di Sébastien MULLIER per la sua riflessione sulla perfezione «d'ordre prosodique» ricercata nella prosa dall'autore di Salammbô, dove l'armonia appare realizzata in termini di misura numerica ("Salammbô" et les poètes de l'art pour l'art, pp. 229-251).

11 Due studi comparativi con realtà letterarie non francesi concludono il volume: Ana Ozores ou le bovarysme espagnol: Leopoldo Alas, dit Clarín, sous l'influence de Flaubert di Virginie PRIOUX (pp. 253-264) e Flaubert et les écrivains japonais: regards croisés (1857-1880) di Marc LEFRANÇOIS (pp. 265-277). 